\title{
Terminal Pregnancy Complicated by Measles and Premature Labor: a Case Report
}

\author{
Yu-chen Zhang, Li Liu and Xiao-li Yang
}

Measles infection in pregnant women is a very dangerous clinical condition. Patients usually had complicated pneumonia, and measles virus could pass through the placenta to the fetus, leading to premature delivery, stillbirth, miscarriage and neonatal measles. In this report, we described one such case, which was diagnosed by clinical signs and symptoms, clinical and laboratory examination. After proper therapeutic treatment, the infection was well-controlled and a baby was born by nature labor.

Key words: Pregnancy trimester, third; Measles; Obstetric labor, premature

$\mathrm{M}$ easles infection in pregnant women is usually dangerous, with complicated pneumonia; measles virus could pass through the placenta to the fetus, leading to premature delivery, stillbirth, miscarriage and neonatal measles. In this paper, we reported one case of terminal pregnancy complicated by measles and premature labor in the Central Hospital of Taian City, Shandong Province, China.

\section{CASE REPORT}

A 37-year-old patient in terminal pregnancy was admitted to our department through our emergency clinic at 8:00 am on March 5th, 2009. She presented with fever for 5 days, rash for 2 days and menopause for 29 weeks. Her body temperature was up to 40 ${ }^{\circ} \mathrm{C}$, with nasal discharge, cough, chest tightness, hold breath, hoarseness, malaise and loss of appetite. Three days before admission, rash appeared firstly behind her ears, around hair line, on face (Figure 1) and gradually spread to the trunk (Figure 2) and limbs. As a result, irregular contractions, then appeared with small amount of vaginal bleeding. Physical examination was as follows: T $39.3{ }^{\circ} \mathrm{C}, \mathrm{P} 88$ beats/min, R 22 times/ $\mathrm{min}, \mathrm{BP} 120 / 70 \mathrm{~mm} \mathrm{Hg}$. The patient presented clear consciousness, poor spirit, hyperemia and edema of eye conjunctiva, congestive throat and rough Koplid's spots. Symptoms were as follows: body with scattered pale red skin rash, rough sound of breath and dry rales

Correspondence: The Central Hospital of Taian, Shandong Province 271000, China

Zhang Yu-chen, Email: zycd1954@163.com in the lungs; regular and strong heart sounds without pathological murmur; abdominal distension, fundus of the uterus three finger up to the umbilicus; both lower extremities without edema. Laboratory tests: WBC $7.12 \times 10^{9} / \mathrm{L}, \mathrm{N} 80.64 \%$, L $12.14 \%$; liver function: ALT $1262 \mathrm{U} / \mathrm{L}$, AST $183 \mathrm{U} / \mathrm{L}$, serum lactate dehydrogenase $531 \mathrm{U} / \mathrm{L}, \alpha$ - hydroxybutyric dehydrogenase $457 \mathrm{U} / \mathrm{L}$; serum measles antibody $\operatorname{IgM} 1: 6400, \operatorname{IgG}<1: 50$ by ELISA assay. Color doppler ultrasound examination showed a single fetus, alive birth and late pregnancy. The diagnosis of measles complicated by bronchial pneumonia, liver damage, 29 weeks of pregnancy and threatened premature labor was confirmed. After admission, penicillin was applied to control infection and magnesium sulfate was used to inhibit uterine contractions in order to prevent miscarriage after obstetric consultation. At 15:00 pm regular contractions appeared with vaginal bleeding and examination showed uterine neck was totally opened. The patient delivered a baby boy naturally under ECG monitoring after regular disinfection of the vulva. The newborn baby showed premature appearance, with loudly crying sound, body mass $1300 \mathrm{~g}$, Apgar score 8 to 9, and then he was sent to the neonatal intensive care unit. Patients with postpartum suppress ease. Antiviral drugs, expectorant, antiasthmatic, liver protection treatment and nutritional supports were applied to the patient. On the 3rd day after admission, her respiratory symptom relieved, rash disappeared gradually, leaving light brown pigmentation with small bran-like desquamation. Also on the 3rd day, the measles antibody IgM was above 1:12 800, IgG above 1:3 200; neonatal cord blood measles antibody IgM and IgG were negative. So 


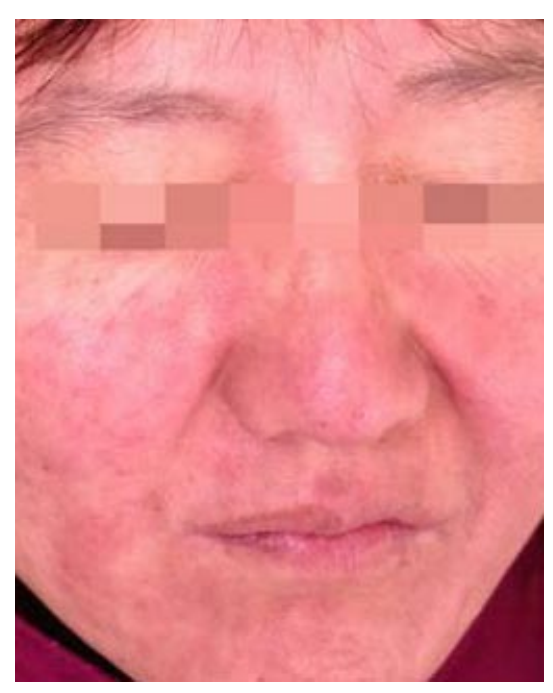

Figure 1. Patient with facial skin rash.

the patient was discharged from our hospital.

\section{DISCUSSION}

With the widespread vaccination of measles vaccine, the age of measles incidence increased. Measles virus infection in pregnant women is usually dangerous, with complicated pneumonia. Also, measles virus could pass through the placenta to the fetus, leading to premature delivery, stillbirth, miscarriage and neonatal measles. In this local epidemic measles case, the patient had a history of close contact with measles patients and was not vaccinated against measles; her body temperature has persisted higher than $39{ }^{\circ} \mathrm{C}$, delivery happened at the 5th day after outbreak (stadium acmes of measles); measles antibody $\operatorname{IgM} 1: 6400, \operatorname{IgG}<1: 50$ before delivery and $\operatorname{Ig} M \geqslant 1: 12800, \operatorname{IgG} \geqslant 1: 3200$ after discharge from hospital. According to the negative results of neonatal cord blood measles antibody IgM and $\mathrm{IgG}$, the diagnosis of late pregnancy complicated with measles was confirmed. Compaction of measles

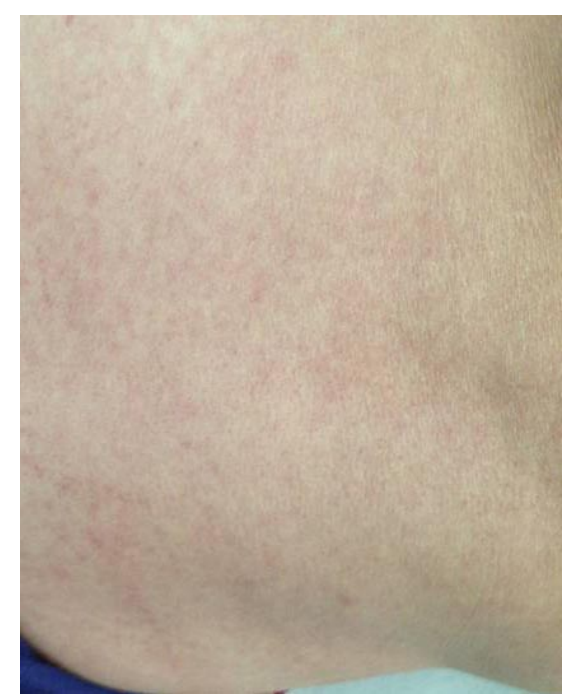

Figure 2. Patient with back skin rash.

during pregnancy was rarely reported. Measles is a systemic disease, and measles viremia can cause inflammation and necrosis of endothelial and epithelial cells, with many tissues and organs being infected, and rash, fever and other symptoms can cause uterine contractions or premature. Therefore, for such patients with measles during pregnancy, antenatal examination is essential and pregnancy should be ended in time by cesarean delivery when fetal distress appeared.

\section{REFERENCES}

1. Mandell GL, Bennett JE, Dolin R, eds, Principles and practice of infectious disease 14th edition. London: Churchill Livingstone, 1995:1519-1526.

2. Li MD. Practice of infectious diseases. (2rd edition). Beijing: People's Medical Publishing House,1998:59-67.

3. Li MD (Chief editor). The utility of infectious diseases (the second edition) Beijing: People's Medical Publishing House, 1998:59-67.

4. Peng B, Wei YJ. Analysis on clinical characteristics of 20 adults with measles. Zhongguo Xian Dai Yi Sheng (Chin) 2007; 5(2):31. 